REVISTA DE LA CEPAL 84 • DICIEMBRE 2004

\section{Las relaciones entre niveles de gobierno en Argentina}

\author{
Oscar Cetrángolo y Juan Pablo Jiménez
}

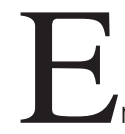

n este artículo se tratan las relaciones fiscales y financieras entre el gobierno nacional y los gobiernos provinciales en Argentina durante los últimos 15 años, identificando aquellos factores que ayudan a explicar su alto grado de conflictividad. Dadas las raíces institucionales del conflicto, se hace una revisión histórica para poner en un contexto de largo plazo los problemas recientes y el debate futuro. En primer lugar, se examina el desarrollo del federalismo en el país y la evolución de las autonomías provinciales. Luego, en el cuerpo central del documento, se pasa revista a las alternativas que en las últimas décadas han dominado los cambios en las funciones y los ingresos de los diferentes niveles de gobierno. Tales alternativas tienen que ver no sólo con el reparto de los impuestos, sino también con el proceso de descentralización y cambio de funciones entre niveles de gobierno.
Oscar Cetrángolo

Experto en políticas sociales,

Oficina de la CEPAL en Buenos Aires

• ocetrangolo@cepal.org.ar

Juan Pablo Jiménez

Consultor,

Oficina de la CEPAL en Buenos Aires

œ jpjimenez@cepal.org.ar 


\section{I}

\section{Introducción}

Es sabido que los beneficios de un moderno sistema federal de gobierno están asociados al efectivo funcionamiento de las instituciones democráticas. En Argentina, no obstante, desde la vuelta a la vigencia de esas instituciones en 1983, el debate se ha centrado casi exclusivamente en la posibilidad de sancionar un nuevo régimen de reparto de impuestos y poco se ha avanzado en el examen de un federalismo fiscal más maduro que facilite una mejor calidad de vida a lo largo de su territorio. Peor aún, ni siquiera se ha logrado un régimen estable de reparto de impuestos. Hace diez años una Asamblea Constituyente estableció la necesidad de un nuevo régimen sobre el cual nunca se pudo llegar a un consenso. Los pactos transitorios, los acuerdos bilaterales (muchas veces secretos) y la desconfianza mutua han reemplazado a las reglas transparentes y estables, la confianza y la complementariedad necesarias en un sistema federal moderno que privilegie el consenso por encima del conflicto.

La reciente crisis y las decisiones tomadas para hacerle frente involucran, sin duda, una modificación en las relaciones entre niveles de gobierno, que afecta tanto a la distribución de recursos e ingresos como a las atribuciones de funciones y el endeudamiento de cada uno de ellos. Se hace necesario, entonces, repensar el problema, buscando en sus raíces las razones de las dificultades pasadas, así como las claves para construir un sistema más sólido a partir de las nuevas circunstancias.

En este artículo se examinará la conflictiva relación financiera entre la Nación y las provincias durante los últimos 15 años, para identificar los factores que explican las dificultades existentes para generar un esquema estable de relaciones entre la una y las otras, esquema del cual la ley de coparticipación es sólo una parte. Teniendo en cuenta las raíces institucionales de esta cuestión, habrá que efectuar una revisión histórica de largo plazo para poner en el contexto apropiado los problemas recientes y el debate futuro.

Respondiendo a esa idea, en la sección siguiente se presentarán las raíces históricas del conflicto entre diferentes niveles de gobierno, analizando el proceso de desarrollo del estado federal como límite a las autonomías provinciales, y la particular historia de los regímenes de reparto de impuestos en Argentina. Luego, el cuerpo central del documento estará destinado a examinar las relaciones entre niveles de gobierno durante los últimos 15 años, tanto por el lado de las funciones como de los recursos. Allí se desarrollarán no sólo las alternativas referidas al reparto de impuestos, sino también las relativas al proceso de descentralización y cambio de funciones entre niveles de gobierno.

\section{II}

\section{Asignación de funciones entre niveles de gobierno}

Argentina, al igual que los Estados Unidos, Suiza y Australia, pertenece al grupo de países cuyas constituciones definen las potestades federales y concurren-

\footnotetext{
$\square$ Los autores agradecen la colaboración de Daniel Vega. El presente artículo es una versión parcialmente modificada de un documento que se presentó en el XVI Seminario Regional de Política Fiscal, organizado por la CEPAL (Santiago de Chile, enero de 2004) y que será publicado próximamente por el Instituto Latinoamericano y del Caribe de Planificación Económica y Social (ILPES)
}

tes, dejando todo aquel poder residual no especificado a cargo de los gobiernos provinciales. Así, la Constitución Nacional argentina establece que las provincias conservan todas las competencias no delegadas al gobierno federal. Como señala Bidart Campos (1993), esto indica que para las provincias la competencia es la regla mientras que para el gobierno federal es la excepción. El gobierno federal tiene responsabilidad exclusiva en materia de relaciones exteriores, emisión de moneda, regulación del comercio, navegación interior y 
exterior, y defensa. En cambio, hay potestades compartidas en varias finalidades, entre las que se cuentan la administración de justicia, la educación primaria y la seguridad social. Como consecuencia, el marco constitucional no es muy preciso en lo que se refiere a las funciones y responsabilidades de cada nivel de gobierno, lo que permitió distintos procesos de reasignación de funciones en las últimas décadas. Esos procesos, no siempre ordenados y transparentes, han hecho más compleja la relación Nación-provincias-municipios.

La Constitución Nacional delega a cada provincia la definición de su propio régimen municipal. Las constituciones provinciales y las leyes orgánicas municipales establecen diferentes áreas de competencia para los municipios, pero en la práctica estas diferencias se han reducido. Las principales acciones y políticas de los gobiernos locales están vinculadas fundamentalmente a los servicios urbanos básicos, tales como los servicios de recolección de residuos y el alumbrado público.

\section{El gasto público y su asignación entre niveles de gobierno}

La falta de una clara división de las responsabilidades de gasto entre los distintos niveles de gobierno suele ser la fuente principal de conflicto entre ellos, aparte de traer aparejado un uso ineficiente y desigual de los recursos. Mientras que algunas funciones suscitan poca discusión sobre qué nivel de gobierno debe proveerlas (por ejemplo, defensa), otras, como educación y salud, han merecido diversas formas de tratamiento en los diferentes países a lo largo de los últimos años. Más allá de que la recomendación habitual suele ser evitar la superposición de funciones, lo usual es que las distintas responsabilidades del sector público sean compartidas entre los diversos niveles de gobierno.

A diferencia de otros países, en Argentina los procesos de devolución o descentralización del gasto hacia los gobiernos subnacionales no pueden ser entendidos como un avance de estos gobiernos sobre el poder central. Si bien, por un lado, se observa que con cada nueva instancia legislativa los coeficientes de reparto a favor de los gobiernos provinciales han aumentado, por otro, los procesos de descentralización del gasto, al no haber sido acompañados por cambios simétricos en los recursos, han requerido de gobiernos centrales fuertes (militares o civiles) y una desigual capacidad de negociación.

Como sucedió hacia finales del decenio de 1970, el proceso de descentralización fiscal que predominó en las reformas educativa y de salud a principios de la década de 1990 tuvo como motivación excluyente la decisión del gobierno nacional de modificar en su favor las relaciones financieras con las provincias y municipios. Tanto la transferencia de establecimientos hospitalarios y de educación primaria en el primero de los decenios mencionados, como la de hospitales y escuelas secundarias de principios del segundo, tuvieron como motivación explícita la de modificar la coparticipación efectiva. Más aún, no se han contemplado recursos específicos para atender al financiamiento de los servicios descentralizados ni se han diseñado mecanismos compensatorios con anterioridad a las transferencias.

La política de descentralización instrumentada ha derivado en serios costos en materia de "cohesión social". Tanto en el campo de la salud como en la provisión de educación se puede identificar una multiplicidad de respuestas locales respecto a la forma que adopta el proceso y a sus resultados en términos de equidad y eficiencia. La falta de coordinación desde el nivel central ha permitido una gran heterogeneidad de conductas a nivel provincial y municipal, que responde a grandes rasgos a la configuración previa de cada sistema y a la política sectorial adoptada en cada lugar en respuesta al propio proceso descentralizador. Estas respuestas, a su vez, están estrechamente condicionadas por la restricción financiera, que opera de manera muy diversa en cada jurisdicción. De esta manera, las posibilidades de mejorar los servicios sociales descentralizados están delimitadas por el grado de desarrollo socioeconómico y productivo y la capacidad de financiamiento de cada una de ellas. A su vez, las potencialidades de desarrollo de cada jurisdicción están determinadas en buena parte por el estado y nivel de su capital humano y cultural, lo cual se vincula directamente con las posibilidades que tenga su población de acceder a buenos niveles de educación y salud.

No hay mecanismos fiscales y financieros particulares, asociados a la distribución de rentas fiscales entre la nación y las provincias, que puedan asimilar pautas de carácter nacional en cuanto a la provisión y calidad de la educación o la salud. Bajo el diseño actual, esto plantea un dilema de difícil solución: si se desea aplicar programas o políticas y prioridades de alcance nacional, orientados a una provisión más equitativa de educación y salud en las diferentes provincias del país, éstas terminarán demandando fondos adicionales del presupuesto nacional; por otro lado, si esta opción no es viable desde el punto de vista fiscal, se perjudicarán las acciones de reaseguro. Como resultado, la provisión y calidad de la educación y la salud tenderán a depender excesivamente de la disponibilidad 
de recursos económicos y fiscales en las diferentes jurisdicciones.

Además, la descentralización de servicios sociales ha hecho que se modifique la modalidad en que se manifiesta la restricción fiscal. Dado que la estructura de gasto provincial ha pasado a estar cada vez más dominada por los servicios sociales, los diversos esfuerzos de saneamiento fiscal emprendidos por diferentes jurisdicciones provinciales que enfrentaron problemas fiscales y financieros debieron, necesariamente, prestar atención a las posibilidades de reducir sus erogaciones en salud y educación. Además, considerando que la casi totalidad de los gastos con esas finalidades se concentra en pago de salarios, esos intentos generaron en algunas provincias episodios de alta conflictividad social. Para atender a estos problemas se intentó aplicar algunas reformas en los sectores de salud y educación tendientes a mejorar la organización y administración del gasto social.

Como resultado de los procesos de cambio en la estructura fiscal del país, el gobierno nacional ha centrado progresivamente sus erogaciones en la previsión social, la salud para la tercera edad y los servicios de la deuda. Las provincias, por su parte, lo han hecho en educación y salud, y los municipios en diferentes servicios urbanos. Simplificando al extremo el problema, podría decirse que la Nación ha concentrado su presupuesto en la atención de los problemas del pasado (en general, derechos adquiridos de difícil reformulación), mientras que las provincias han concentrado los suyos en el futuro. De hecho, el gobierno nacional ha utilizado como argumento las necesidades financieras del sistema de pensiones para presionar a los gobiernos provinciales y convenir con ellos la cesión de recursos que aseguren el financiamiento de la previsión social. Como consecuencia, tanto las provincias como los municipios están hoy cofinanciando el sistema previsional. Para ilustrar este punto, en el gráfico 1 se presenta el nivel y composición del gasto de los diferentes niveles de gobierno para los años 2000 y 2002 (antes y después del fin del programa de convertibilidad). Allí se pueden verificar las características antes señaladas en relación con la estructura funcional del gasto por niveles de gobierno.

GRAFICO 1

Argentina: Composición del gasto público por finalidad y nivel de gobierno, 2000 y 2002

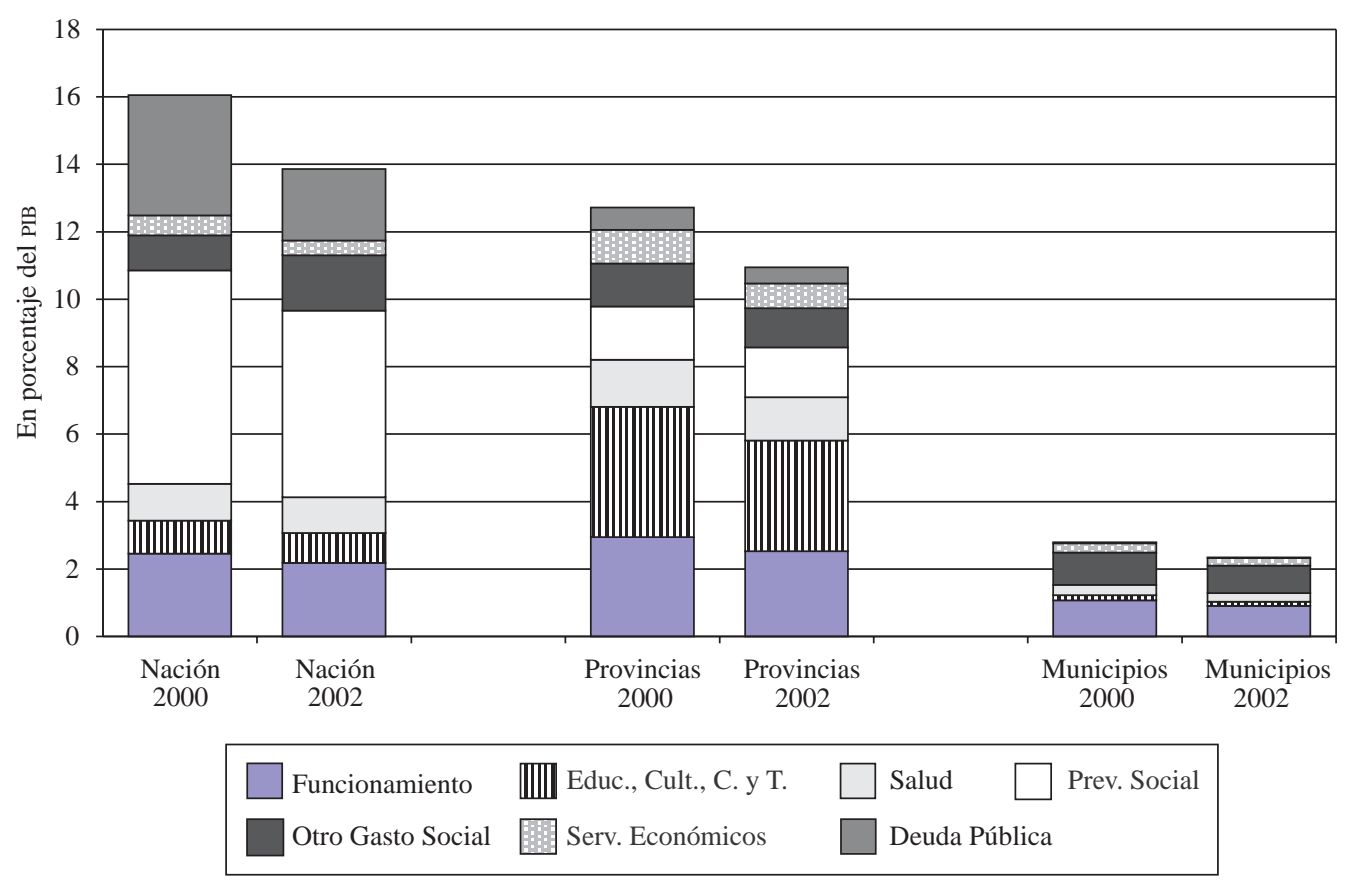

Fuente: Elaboración propia en base a datos de la Secretaría de Política Económica. 


\section{Asignación de potestades tributarias y desbalance financiero interjurisdiccional}

En cuanto al financiamiento de los distintos niveles de gobierno, la Constitución Nacional (artículo 75, inciso 2), delimita las potestades tributarias de la Nación y las provincias, estableciendo que los impuestos indirectos son concurrentes entre ambos niveles, salvo en lo que respecta a los gravámenes de importación y exportación, que son exclusivamente nacionales (artículo 4). Los impuestos directos son exclusivamente provinciales, pero la Nación tiene la posibilidad de utilizarlos durante un plazo limitado y siempre que la defensa, la seguridad común y el bien general del Estado lo exijan.

En la práctica, la mayoría de los tributos los recauda la Nación y las provincias coparticipan de ellos. Estas últimas, por su parte, se han quedado con cuatro impuestos principales (inmobiliario, automotor, a los sellos y a los ingresos brutos), que les permiten recaudar en promedio el equivalente a un $40 \%$ de sus gastos; el resto lo financian mediante transferencias del gobierno central y endeudamiento.

En este sentido, Argentina no escapa a la que ha sido la tendencia internacional: la participación de los gobiernos subnacionales en los recursos totales no ha crecido en proporción con el aumento del gasto de esos gobiernos, lo que se ha traducido en una creciente brecha entre gasto y recursos a nivel subnacional.

Por razones de eficiencia, la literatura suele recomendar que los gobiernos subnacionales no utilicen impuestos sobre bases tributarias con alta movilidad y sujetas a importantes variaciones cíclicas. Esto claramente limita la descentralización de los impuestos sobre los ingresos, ya sea de las personas o de las empresas. Respecto a los impuestos al consumo, consideraciones de administración tributaria (economías de escala en la recaudación y dificultades en el comercio entre jurisdicciones) hacen también poco recomendable su descentralización. Los impuestos al patrimonio, que evitan todos estos problemas, suelen generar recaudaciones de montos poco significativos para financiar los gastos de los niveles subnacionales en países fuertemente descentralizados.

La asignación de los tributos entre niveles de gobierno debe balancear dos objetivos, a veces enfrentados. Por un lado, la teoría del federalismo fiscal nos indica que los gobiernos subnacionales pueden responder mejor a las preferencias de los habitantes en aquellos lugares donde los impuestos locales permiten internalizar los costos de proveer determinada cantidad de bienes y servicios por parte del gobierno local.

Por otro lado, diversos motivos hacen difícil la asignación a los gobiernos nacionales de potestades tributarias suficientes para financiar la creciente provisión de bienes y servicios por estos gobiernos. Con lo cual, si bien existe acuerdo teórico sobre la necesidad de que haya cierta simetría entre las responsabilidades de gasto y las potestades tributarias, en la práctica existen pocos impuestos que puedan ser descentralizados sin una importante pérdida de eficiencia y equidad.

Este compromiso entre dos objetivos, que a veces se contraponen, puede ser mitigado con una adecuada coordinación tributaria entre los niveles de gobierno. Por otro lado, un efectivo diseño del sistema de transferencias, que plantee objetivos explícitos y genere los incentivos adecuados, puede complementar la habitual deficiencia de los sistemas tributarios subnacionales para financiar las competencias que se les han asignado. No obstante, como se verá en secciones posteriores, esta tarea puede tropezar con numerosos inconvenientes.

Con una visión de largo plazo, es necesario señalar que este desequilibrio financiero interjurisdiccional debe ser también considerado como un elemento que ha agregado conflictividad a las relaciones entre la Nación y las provincias. Como se observa en el gráfico 2, los desbalances entre las estructuras jurisdiccionales de gastos y los recursos tributarios y no tributarios eran muy poco significativos hasta la década de $1980 .{ }^{1}$ Desde entonces, la mayor concentración de recursos administrados por la Nación y la descentralización de erogaciones generaron una fuerte presión sobre los sistemas de reparto de tributos, al concentrarse en la Nación las tres cuartas partes de los recursos y cerca de la mitad de las erogaciones consolidados. Antes de la descentralización de escuelas y hospitales ocurrida a fines del decenio de 1970, el gobierno nacional recaudaba y gastaba una proporción bastante similar del total.

\footnotetext{
${ }^{1}$ Lamentablemente, no es tarea sencilla reconstruir las estadísticas fiscales de largo plazo en Argentina. Para elaborar el gráfico 2 se utilizaron diferentes publicaciones de la Secretaría de Hacienda, que a lo largo del tiempo han ido presentando la información con diversa metodología. En esta oportunidad se trató de transformar los datos de acuerdo con una metodología homogénea y se eligieron los años teniendo en cuenta los cambios de niveles de descentralización de recursos y erogaciones, pero también la propia disponibilidad de información. Entre los recursos se incluyeron, además de los tributarios, los no tributarios propiamente dichos (tasas y contribuciones percibidas en pago por servicios prestados) para permitir una mejor apreciación del financiamiento municipal.
} 
GRAFICO 2

Argentina: Estructura porcentual de recursos (tributarios y no tributarios) y de erogaciones, por nivel de gobierno ${ }^{a}$

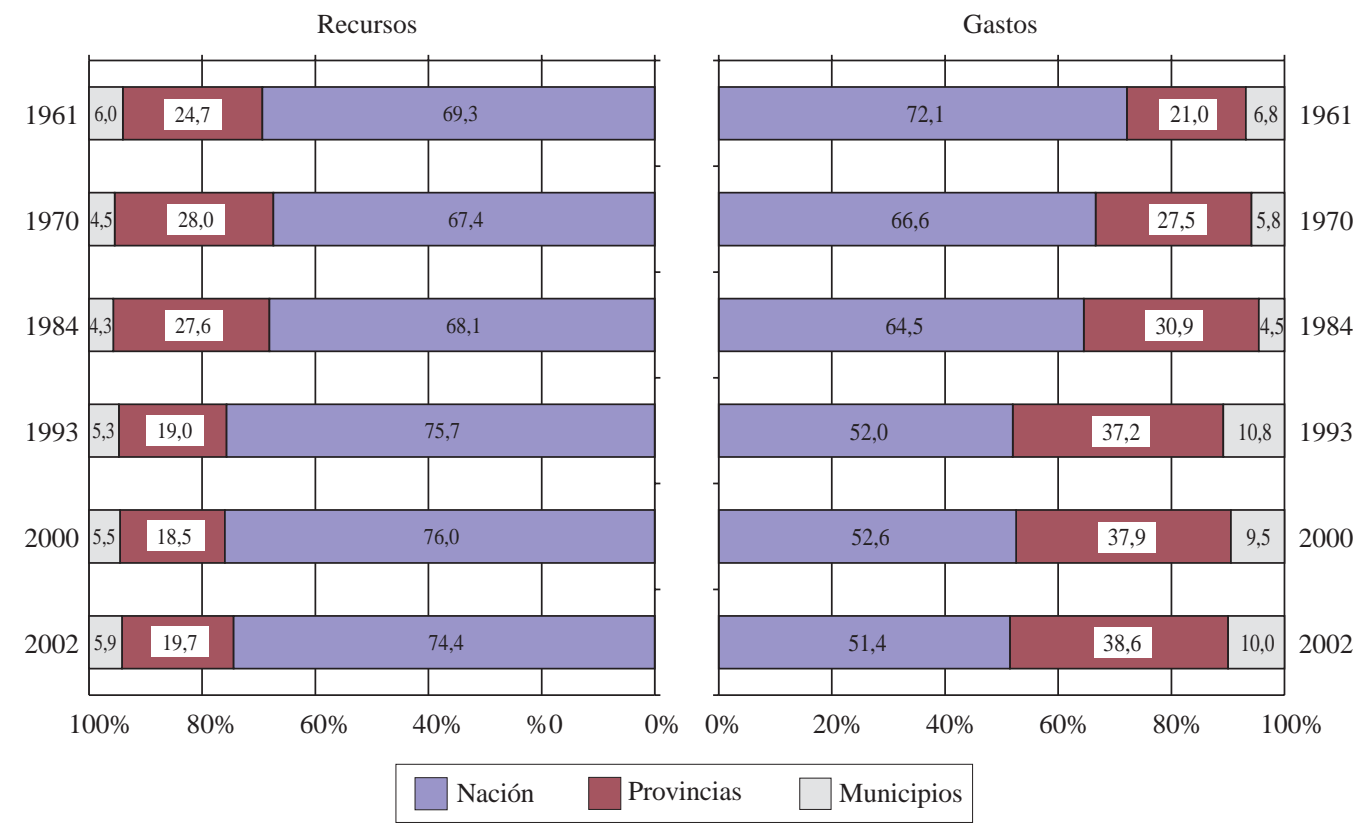

Fuente: Elaboración propia basada en datos de la Secretaría de Hacienda.

a Los recursos corresponden a los tributarios y no tributarios administrados por cada nivel. Las erogaciones se clasificaron de acuerdo con el nivel de gobierno que las ejecuta. En el caso de las empresas públicas se consideraron como erogaciones del nivel correspondiente los pagos de intereses y el déficit primario.

Por último, se estima importante, para completar el análisis de las fuentes de financiamiento, examinar la capacidad de autonomía provincial y la disponibilidad de recursos tributarios propios, y considerar brevemente sus disparidades productivas, la dinámica de sus economías reales y algunos problemas específicos de desarrollo económico en las diferentes jurisdicciones.

Estudios recientes sugieren que la convergencia de los ingresos per cápita entre los países de la Unión Europea no ha tenido su correlato en una convergencia entre jurisdicciones subnacionales. Por el contrario, las diferencias en los ingresos per cápita entre tales jurisdicciones se han incrementado en Italia, Alemania y Francia (Decressin, 1999). Un resultado parecido para América Latina señala Silva (2003). No obstante, debe tenerse en cuenta que la magnitud de tales disparidades varía mucho de un país a otro. Así, en Argentina el ingreso per cápita de la provincia de
Santa Cruz (la más rica según ese indicador) es 8,6 veces mayor que el de Formosa (la más pobre); en Brasil el ingreso per cápita es 7,2 veces mayor en el distrito federal que en el estado de Maranhão, en México 6,2 veces mayor en el distrito federal que en Chiapas, y en Canadá solo 1,7 veces mayor en el estado más rico que en el más pobre. Estas grandes disparidades en términos subnacionales no sólo impactan en el diseño de los esquemas de igualación, sino que ponen un límite a ciertos ejercicios descentralizadores. Asimismo, se traducen en diferentes bases imponibles para financiar una determinada provisión de bienes y servicios a cargo de los sectores públicos subnacionales, y en diferentes capacidades entre los aparatos de gobierno. Todo ello contribuye a marcar la importancia que revisten los mecanismos de transferencias hacia los gobiernos subnacionales, lo que será analizado a continuación. 


\section{III}

\section{La estructura federal fiscal en Argentina y la coparticipación en los impuestos: raíces históricas de los conflictos y consensos entre niveles de gobierno}

\section{Raíces históricas de los conflictos entre juris- dicciones}

Durante un largo período posterior a su independencia, en Argentina se generó una tensión entre las dos tendencias que predominaron en los intentos constituyentes (la confederación de autonomías provinciales y la federación con hegemonía nacional) y que se manifestaron en una serie de pactos y acuerdos. ${ }^{2}$ Sólo en la segunda mitad del siglo XIX se resolvió, con la Constitución de 1853, la organización federal con hegemonía nacional. No obstante, la tensión con las autonomías provinciales continuaría existiendo (Botana, 1993). A partir de 1935, las relaciones entre la Nación y las provincias han girado alrededor de la distribución de los recursos tributarios, habiendo sido escasos los esfuerzos de coordinación del gasto y el endeudamiento. Precisamente, en la presente sección nos ocuparemos de manera específica del reparto de ingresos y los regímenes de coparticipación de impuestos.

Es habitual que se identifiquen las disputas alrededor de la coparticipación de impuestos con los conflictos por el financiamiento de las actividades de los diferentes niveles de gobierno. No obstante, la historia de los regímenes de coparticipación es sólo la tercera (y sin duda la más conocida) de las etapas en que se desarrollaron esas disputas. Antes, desde mediados del siglo XIX hasta 1890, los diferentes niveles de gobierno tenían una clara separación de fuentes tributarias: los recursos de la Nación provenían básicamente del comercio exterior, mientras que las provincias recurrían a impuestos sobre la producción y el consumo de bienes específicos. Luego, entre 1890 y 1935, con la creación de impuestos nacionales sobre los consumos que se superponían a los provinciales,

\footnotetext{
${ }^{2}$ El Pacto Federal de 1831 fue una clara expresión de la voluntad confederada.
}

se desarrolló la segunda etapa, "de concurrencia de hecho". ${ }^{3}$

El régimen de coparticipación de impuestos nació en 1935 con la aprobación de las leyes que determinaron la expansión de la masa de recursos recaudados por la Nación para hacer frente a las dificultades fiscales causadas por la caída de los recursos provenientes del comercio exterior durante la crisis de la década de 1930.

Posteriormente, en la década de 1950, se configuró el régimen de coparticipación que rigió hasta 1973. Este se caracterizaba por la existencia de varias leyes que establecían la distribución de los diferentes tributos y que definieron tres mecanismos distintos de reparto. Sólo a partir de 1973 el régimen de coparticipación pasó a estar regulado por una única norma, la ley 20.221. El esquema establecido en esta norma resultó novedoso en dos sentidos: estaba constituido por un sistema único de distribución de impuestos coparticipados, y determinaba coeficientes de reparto secundario en los cuales cobraban cierta importancia los criterios redistributivos. Los rasgos descritos convirtieron a este régimen en referencia obligada cada vez que se discuten nuevos mecanismos de reparto.

Luego, la crisis macrofiscal de principios de la década de 1980 generaría serios problemas de financiamiento a los gobiernos provinciales. Con nuevos gobiernos democráticos en la Nación y las provincias, el conflicto entre jurisdicciones alcanzaría un nivel tal, que al finalizar la vigencia de la ley 20.221 no fue posible convenir un nuevo régimen durante tres años (entre 1985 y 1987) y sólo en el último de estos años, luego de una derrota electoral del partido a cargo del gobierno nacional, se pudo negociar un régimen transitorio, el de la ley 23.548, que está vigente hasta hoy, aunque con múltiples modificaciones.

\footnotetext{
3 Véase más al respecto en Porto (1990), Presman (1992) y Cetrángolo y Jiménez (1998).
} 


\section{Los sistemas de reparto en el largo plazo}

Como reflexión general, la evolución de largo plazo de los sistemas de coparticipación de impuestos recaudados por la Nación se caracterizó por la acción de tres tendencias simultáneas: el aumento de las jurisdicciones subnacionales incluidas; la creciente incorporación de tributos nacionales en la masa de recursos en los que se coparticiparía, y el aumento del coeficiente de distribución primaria. ${ }^{4}$

La primera de esas tendencias se refleja en el cuadro 1. Allí se observa que de las 24 jurisdicciones provinciales hoy existentes (incluida la Ciudad de Buenos Aires), sólo 14 habían participado en la formación del Estado federal. Se trata de las provincias que habían formado parte de alguna de las gobernaciones con las que el Reino de España había organizado el territorio de la actual República Argentina, de modo que eran anteriores a $1853 \mathrm{y}$, por supuesto, a la aprobación de las primeras leyes de reparto de impuestos hacia mediados del decenio de 1930.

Las restantes provincias actuales corresponden a los llamados Territorios Nacionales (previamente bajo jurisdicción de la Gobernación de Buenos Aires), lo que terminó por definir un país de organización federal, pero con una vasta extensión (en especial luego de la "Conquista del Desierto" del decenio de 1880) bajo una organización de tipo unitaria, con nueve gobernaciones dependientes del poder central. ${ }^{5}$ En el cuadro 1 también se puede observar el peso relativo, en términos de población y generación de riqueza, adquirido por esos territorios que hace 150 años no revestían importancia en esos dos aspectos. En las provincias creadas durante la década de 1950 y Tierra del Fuego habita hoy algo más del $12 \%$ de la población total del país y en ellas se genera una proporción similar del PIB total. La Ciudad de Buenos Aires, si bien fue declarada autónoma en 1994, pertenecía a mediados del siglo XIX a la provincia del mismo nombre.

El cuadro 1 brinda asimismo una imagen elocuente de un rasgo destacado del federalismo y la economía argentinos: la fuerte concentración de la riqueza en muy pocas jurisdicciones. Los orígenes del conflicto entre el "puerto" y el interior del país siguen manifestándose, con algunas variantes, en una economía que

\footnotetext{
${ }^{4}$ Una excepción a esa tendencia fue la reforma de 1967, cuando se redujo el coeficiente de distribución primaria.

${ }^{5}$ En aquel entonces, una porción de las provincias de Salta y Jujuy también eran parte de un Territorio Nacional, el Territorio de Los Andes. Véase Botana (1993), p. 241.
}

CUADRO 1

Argentina: Año de creación e importancia relativa de las provincias argentinas

\begin{tabular}{|c|c|c|c|}
\hline Jurisdicción & $\begin{array}{l}\text { Año de } \\
\text { creación }\end{array}$ & $\begin{array}{l}\text { Estructura } \\
\text { (\% de población } \\
\text { en 2001) }\end{array}$ & $\begin{array}{l}\text { Estructu } \\
(\% \text { del P } \\
\text { en } 2002\end{array}$ \\
\hline \multicolumn{4}{|c|}{ Creadas antes de 1853} \\
\hline Buenos Aires & 1820 & 38,1 & 32,7 \\
\hline Catamarca & 1821 & 0,9 & 1,1 \\
\hline Córdoba & 1820 & 8,5 & 8,1 \\
\hline Corrientes & 1821 & 2,6 & 1,2 \\
\hline Entre Ríos & 1821 & 3,2 & 2,1 \\
\hline Jujuy & 1834 & 1,7 & 0,8 \\
\hline La Rioja & 1820 & 0,8 & 0,5 \\
\hline Mendoza & 1820 & 4,4 & 3,9 \\
\hline Salta & 1821 & 3,0 & 1,6 \\
\hline San Juan & 1820 & 1,7 & 0,8 \\
\hline San Luis & 1820 & 1,0 & 1,0 \\
\hline Santa Fe & 1815 & 8,3 & 8,1 \\
\hline Santiago del Estero & 1820 & 2,2 & 0,9 \\
\hline Tucumán & 1821 & 3,7 & 1,8 \\
\hline Subtotal & & 80,0 & 64,6 \\
\hline
\end{tabular}

Creadas en la década de 1950

$\begin{array}{lrrr}\text { Chaco } & 1951 & 2,7 & 1,2 \\ \text { Chubut } & 1955 & 1,1 & 2,1 \\ \text { Formosa } & 1955 & 1,3 & 0,5 \\ \text { La Pampa } & 1951 & 0,8 & 1,0 \\ \text { Misiones } & 1953 & 2,7 & 1,2 \\ \text { Neuquén } & 1955 & 1,3 & 2,9 \\ \text { Río Negro } & 1955 & 1,5 & 1,4 \\ \text { Santa Cruz } & 1955 & 0,5 & 1,8 \\ \text { Subtotal } & & 12,1 & 12,0\end{array}$

Creadas en la década de 1990

$\begin{array}{lccr}\text { Gobernación de la } & 1994 & 7,7 & 22,7 \\ \begin{array}{l}\text { Ciudad de } \\ \text { Buenos Aires }\end{array} & & \\ \text { Tierra del Fuego } & 1990 & 0,3 & 0,7 \\ \text { Subtotal } & & 7,9 & 23,4\end{array}$

Fuente: Elaboración propia sobre la base de información del Consejo Federal de Inversiones (1996), el Instituto Nacional de Estadística y Censos (INDEC) y la Oficina de la CEPAL en Buenos Aires.

concentra el $60 \%$ de su producto en tan sólo dos jurisdicciones (la Ciudad y la provincia de Buenos Aires) y alcanza el $80 \%$ del total en cinco (las mencionadas más Córdoba, Santa Fe y Mendoza). En el otro extremo, nueve provincias con estructuras productivas menos desarrolladas no alcanzan a representar en conjunto el $7 \%$ del PIB. ${ }^{6}$

\footnotetext{
${ }^{6}$ De acuerdo con estimaciones realizadas por la Oficina de la CEPAL en Buenos Aires para el Panorama Económico Provincial, disponible en el sitio web de esa oficina. Para más información véase Gatto y Cetrángolo (2003).
} 
La segunda de estas tendencias puede ser comprobada en el cuadro 2, que presenta el tránsito desde un régimen primitivo y fragmentado, que involucraba a sólo tres de los tributos recaudados por la Nación, hasta la aprobación de regímenes unificados que trataron de ordenar la distribución de la casi totalidad de los impuestos recaudados por la Dirección General Imposi- tiva (DGI). El gráfico 3, por su parte, muestra la importancia relativa de los tributos incorporados a la masa coparticipable.

Con relación a la tercera de las tendencias mencionadas, en el cuadro 3 se muestra la evolución de los coeficientes de distribución primaria entre 1935 y 1988. Hasta 1972 la información presentada corresponde a

Argentina: Incorporación de tributos al sistema de coparticipación

\begin{tabular}{|c|c|c|}
\hline Año & Ley & Tributos incorporados \\
\hline 1935 & $\begin{array}{ll}12 & 139 \\
12 & 143 \\
12 & 147\end{array}$ & $\begin{array}{l}\text { Internos. } \\
\text { Sobre las ventas. } \\
\text { Sobre los réditos. }\end{array}$ \\
\hline 1946 & 12956 & Sobre ganancias eventuales y beneficios extraordinarios. \\
\hline 1951 & 14060 & Sustitutivo de la transmisión gratuita de bienes. \\
\hline 1973 & 20221 & $\begin{array}{l}\text { Sobre tierras aptas para explotación agropecuaria, regularización patrimonial, divisas, parque automotor, va- } \\
\text { lores mobiliarios, aceites lubricantes y los que en el futuro establezca la Nación como impuestos indirectos. } \\
\text { También serán incluidos los de asignación específica una vez finalizado el objetivo de su creación. }\end{array}$ \\
\hline 1988 & 23548 & $\begin{array}{l}\text { Todos los impuestos nacionales existentes o por crearse, con las siguientes excepciones: i) derechos de impor- } \\
\text { tación y exportación; ii) aquellos cuya distribución esté prevista en otros regímenes; iii) aquellos con afectación } \\
\text { específica al momento de promulgarse esta norma. Cumplido el objetivo de su creación, se incorporarán al esquema. }\end{array}$ \\
\hline
\end{tabular}

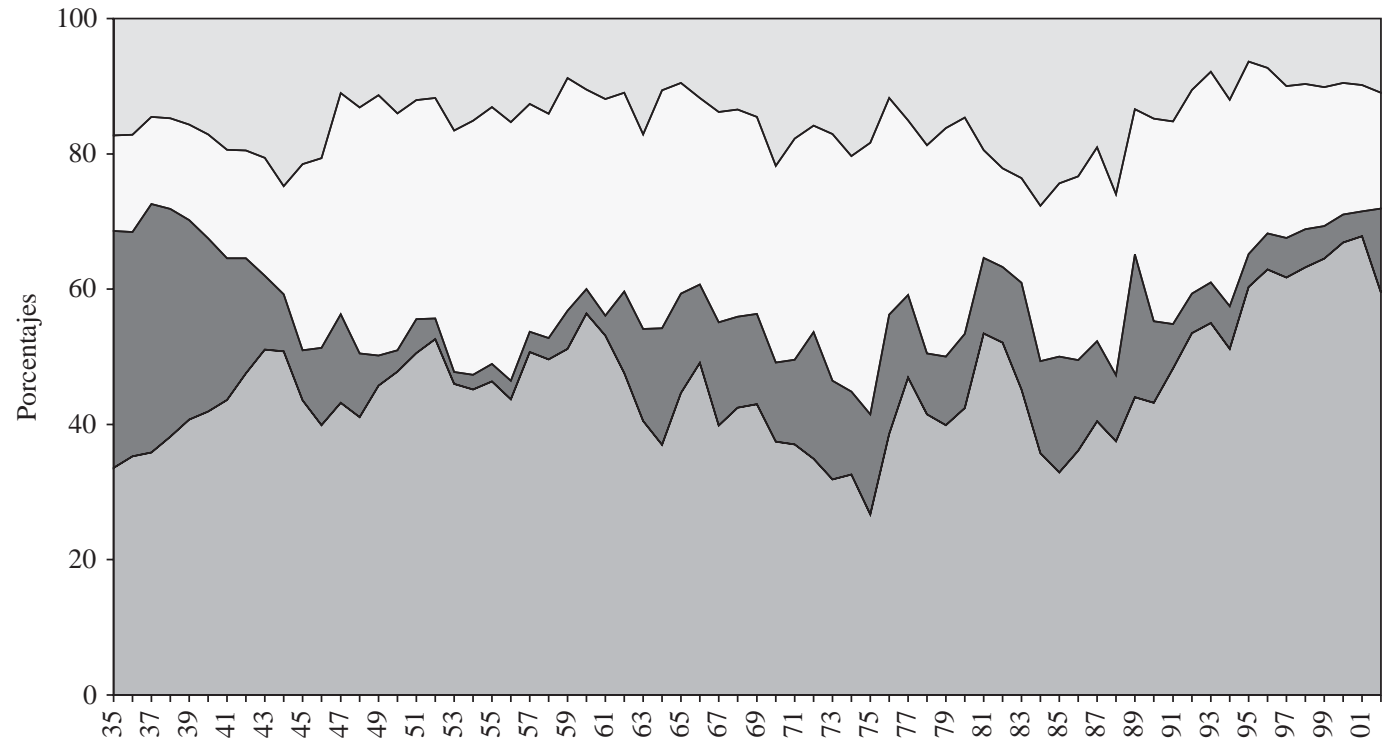

\section{Coparticipables \\ Sobre el comercio exterior \\ Sobre la nómina salarial \\ Otros}

Fuente: Elaboración propia en base a datos de la Secretaría de Hacienda y de Cetrángolo y Jiménez (1995). 
CUADRO 3

Argentina: Evolución de los coeficientes de distribución primaria hasta $1973^{\mathrm{a}}$ y Régimen Federal de Coparticipación desde entonces (Porcentajes)

\begin{tabular}{lccc}
\hline Leyes & Período & Nación & $\begin{array}{c}\text { Provincias y } \\
\text { Municipalidad } \\
\text { de la Ciudad } \\
\text { de Buenos Aires }\end{array}$ \\
\hline 12.143 y 12.147 & $1935-1946$ & 82,5 & 17,5 \\
12.956 & $1947-1958$ & 79,0 & 21,0 \\
14.788 & 1959 & 66,0 & 34,0 \\
& 1960 & 64,0 & 36,0 \\
& 1961 & 62,0 & 38,0 \\
& 1962 & 60,0 & 40,0 \\
20.221 & 1963 & 58,0 & 42,0 \\
23.548 & $1964-1966$ & 54,0 & 46,0 \\
& 1967 & 59,2 & 40,8 \\
& $1968-1972$ & 61,9 & 38,1 \\
& $1973-1980$ & 46,7 & $53,3^{\mathrm{b}}$ \\
& $1981-1984^{\mathrm{c}}$ & 48,5 & $51,5^{\mathrm{d}}$ \\
& 1988 & 42,34 & $57,66^{\mathrm{e}}$ \\
\hline
\end{tabular}

Fuente: Cetrángolo y Jiménez (1998), sobre la base de la legislación.

a Sistema de la Ley 12.143 y de la Ley 12.147 (y modificatorias)

b Incluye $1,8 \%$ destinado a la Municipalidad de la Ciudad de Buenos Aires, financiado por la Nación y el Fondo de Desarrollo Federal.

c Los fondos de coparticipación sufrieron una detracción con destino a la seguridad social.

d Incluye el Fondo de Desarrollo Regional.

e Incluye aportes del Tesoro Nacional.

sólo uno de los regímenes de coparticipación que rigieron de manera simultánea, ya que los restantes no funcionaron con coeficientes fijos. En el cuadro mencionado se puede verificar el crecimiento de la participación de las provincias en la distribución primaria de recursos coparticipables a lo largo del tiempo, salvo en el período comprendido entre 1967 y 1972, durante el cual no funcionó el Parlamento.

No obstante, el análisis de la participación del monto de recursos destinados a las provincias en el total de ingresos tributarios recaudados por la Nación no muestra una evolución ascendente desde 1935, como lo haría suponer la operación de las dos tendencias de largo plazo antes señaladas (la creciente incorporación de tributos a la masa de coparticipación y el aumento de los coeficientes de distribución primaria). Por el contrario, dicha evolución ha sido errática.

Las causas de ese fenómeno se deben buscar en los grandes cambios experimentados por la estructura y nivel de la tributación argentina a lo largo del tiempo. Sin duda, el desarrollo del sistema de seguridad social ha sido una de las razones de lo sucedido, junto con las fluctuaciones cíclicas de la presión tributaria sobre el comercio exterior y la evolución de los otros esquemas de asignación específica de impuestos.

\section{El régimen de coparticipación federal de im- puestos durante los últimos 15 años}

La década de 1980 se inició con el fracaso del intento de construir un régimen sólido y dinámico de coparticipación en los recursos tributarios, y finalizó con la sanción de un nuevo régimen que desde su creación fue definido como provisional. En efecto, hacia fines de 1987 la Ley 23.548 estableció un régimen transitorio de distribución de recursos tributarios entre la Nación y las provincias.

La nueva norma implicó importantes modificaciones en la distribución de recursos primaria (entre el gobierno nacional y las provincias) y secundaria (entre las provincias). En el primer caso hubo mayor participación de las provincias en el reparto de fondos, porque el porcentaje que se distribuiría a las provincias fue el más alto desde 1935 (año del primer régimen de coparticipación), y se amplió la lista de impuestos que integran la masa tributaria coparticipable, alcanzando incluso a los tributos que se pudieran crear con posterioridad a la aprobación de la norma.

En cuanto al reparto secundario, la principal diferencia con la norma anterior (la Ley 20.221, vigente entre 1973 y 1984) es el abandono de todo criterio explícito para el establecimiento de los coeficientes de distribución. En aquella norma el reparto resultaba de la combinación de criterios claramente definidos (población, brechas de desarrollo y dispersión de población). En cambio, los coeficientes establecidos en la Ley 23.548 se basan en las distribuciones efectivamente realizadas durante el período 1985-1987, cuando no existía norma que rigiera la coparticipación y —más importante - cuando el reparto se realizaba de acuerdo con las necesidades de cada jurisdicción y el poder de negociación de los gobiernos y legisladores de las diferentes jurisdicciones, aunque tomando como base la distribución heredada de la antigua Ley 20.221. ${ }^{7}$

\footnotetext{
${ }^{7}$ A lo largo de la historia, los diferentes regímenes han ido incorporando cada vez más criterios redistributivos de reparto secundario, en detrimento de los devolutivos. En consecuencia, ha perdido importancia relativa la participación de las jurisdicciones con mayor capacidad recaudatoria. Este tema fue desarrollado en Cetrángolo y Jiménez (1995).
} 
Durante la vigencia de la Ley 23.548, en la evolución de la recaudación tributaria influyó fuertemente el desarrollo de la situación económica global. En la primera mitad del decenio de 1990 se pudo observar una importante simplificación de la estructura de los recursos coparticipados, la que se revirtió parcialmente a partir de mediados del decenio, cuando hubo que introducir nuevos impuestos de emergencia para enfrentar sucesivos episodios de crisis macrofiscal.

En el gráfico 4 se muestra cómo evolucionó la recaudación en la década de 1990. En él se observa que la carga tributaria fue relativamente constante entre 1992 y 2002 (período en el cual los cambios tributarios y la introducción de nuevos impuestos lograron apenas mantener el nivel de la carga total), y que tuvo un espectacular crecimiento en 2003. A su vez, esa evolución da cuenta de cambios en la estructura tributaria como resultado de una dirección inicial hacia la simplificación del sistema, con el crecimiento relativo de las recaudaciones del impuesto sobre el valor agregado (IVA) ${ }^{8} \mathrm{y}$, en menor medida, de aquel sobre las ganancias. ${ }^{9}$ Luego, en la segunda mitad de la década, se observa una fuerte caída de los impuestos sobre la nómina salarial.

En contraste con esa tendencia, el sistema de distribución de la recaudación tributaria ha cobrado una complejidad y fragilidad difíciles de encontrar en otro período de la historia argentina. Como se verá, al concentrarse la recaudación en impuestos que según la ley vigente son coparticipables, se ha desatado una puja por el destino de esos fondos y se ha alentado la búsqueda de mecanismos para eludir la legislación. A partir de 1996, el incremento en la recaudación que debía ser repartida (de acuerdo con la Ley 23.548) no se tradujo en un aumento de las transferencias a las provincias, sino que sirvió para compensar la pérdida de recursos que corresponden al gobierno central provenientes de impuestos sobre la nómina salarial.

En síntesis, los rasgos salientes de las transferencias a las provincias en la década de 1990 fueron los siguientes: un fuerte aumento en los primeros años; el crecimiento simultáneo de la participación de asignaciones específicas en el total de las transferencias a las

GRAFICO 4

Argentina: Nivel y estructura de la recaudación tributaria total, 1990-2003

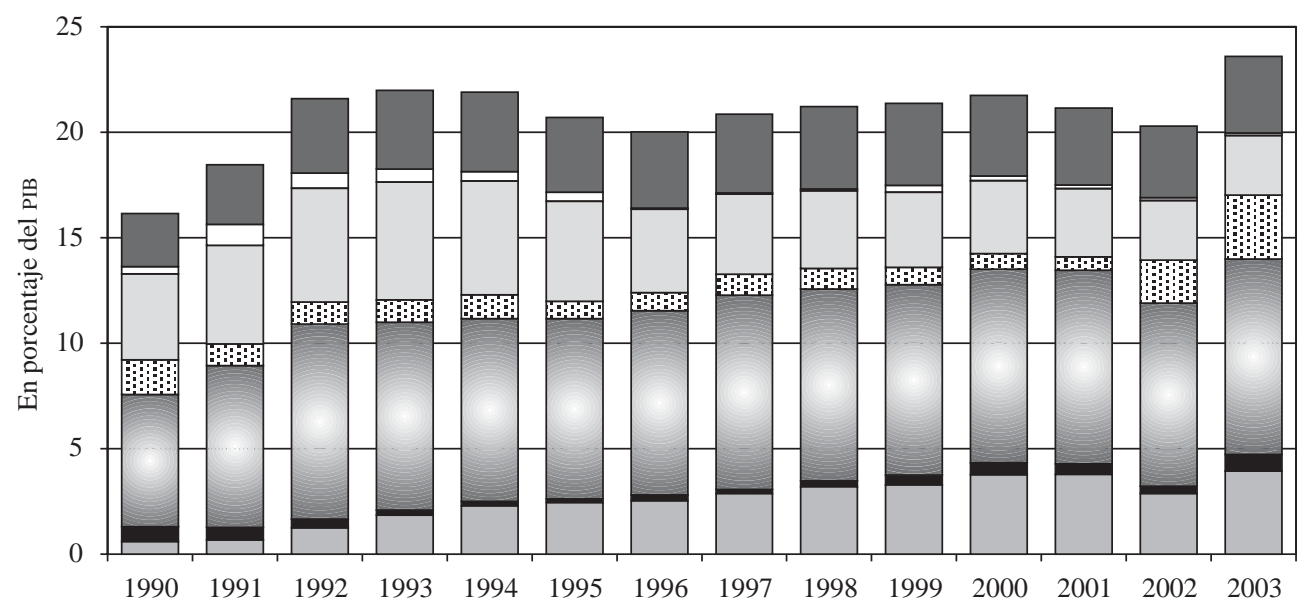

\begin{tabular}{|ll|}
\hline Ingresos, beneficios y ganancias de capital & $\square$ Salarios y contribuciones a la seguridad social \\
Patrimonios & $\square$ Otros recursos tributarios \\
$\square$ Tributos internos sobre bienes, servicios y transac. & $\square$ Recursos provinciales \\
$\square$ Comercio exterior y transacciones internacionales & \\
\hline
\end{tabular}

Fuente: Elaboración propia en base a datos de la Secretaría de Hacienda y la Oficina de la CEPAL en Buenos Aires.

\footnotetext{
${ }^{8}$ Que se incluye en los tributos internos sobre bienes, servicios y transacciones.
}

\footnotetext{
${ }^{9}$ Que se incluye en los tributos sobre ingresos, beneficios y ganancias de capital.
} 
provincias, en detrimento de la coparticipación; el hecho de que las transferencias totales se hayan mantenido constantes a partir de 1992, con independencia de los cambios en la recaudación total, y relacionado en parte con lo anterior, el reemplazo de impuestos sobre la nómina salarial por tributos recaudados por la Dirección General Impositiva en el financiamiento de la Nación.

La puja entre las diferentes áreas de los sectores públicos nacional y provinciales por conseguir recursos fue de tal magnitud que hoy ya casi no queda tributo que no tenga, al menos parcialmente, algún tipo de asignación específica. En respuesta a estas presiones las autoridades nacionales negociaron asignaciones específicas (fundamentalmente al sistema previsional) para sufragar gastos que de otra manera hubiera asumido el Tesoro Nacional, o transfirieron gastos a otros niveles de gobierno (escuelas y hospitales). El resultado fue un cambio en el "reparto efectivo" para llegar a un esquema de distribución de impuestos que surgió de múltiples "remiendos". Estos "remiendos" han ido creciendo en variedad y magnitud a lo largo de los años transcurridos desde que se aprobó la ley de coparticipación virtualmente en vigencia.

A fines de 1999 se firmó el Compromiso Federal, que estableció una suma fija para el año 2000 (por un monto de 1.350 millones de pesos) y un promedio trienal (con un piso mensual de 1.364 millones de pesos) para el 2001. Más tarde, en noviembre de 2000, se firmó otro Compromiso Federal entre la Nación y las provincias en el marco de un nuevo programa conocido como "blindaje". Este acuerdo reemplazó los promedios móviles por sumas fijas durante los años siguientes, hasta que se sancionara una nueva ley de coparticipación.

La situación macroeconómica y fiscal sufrió un fuerte deterioro desde mediados de 2001. A partir del tercer trimestre de ese año, las dificultades para lograr financiamiento obligaron al gobierno nacional a adoptar un programa encaminado a asegurar el equilibrio fiscal mes a mes mediante el anuncio de una estricta regla de caja denominada "déficit cero". Como parte del mismo programa, el gobierno nacional negoció con las provincias una "Segunda Addenda" al Compromiso Federal de noviembre de 2000 que establecía una reducción en las transferencias del orden del 13\%, y se puso en marcha un esquema de canje voluntario de deuda. De allí en adelante los diferentes niveles de gobierno tuvieron serias dificultades para cumplir con sus obligaciones, y en varias jurisdicciones reaparecieron importantes atrasos en el pago de los salarios.
Además, se extendió rápidamente la práctica de pagar obligaciones con bonos, proliferando una gran variedad de medios de pago. El fracaso del programa de "déficit cero" y una suma de factores de orden político y social derivaron en una profunda crisis política que quedó de manifiesto con los relevos de diferentes elencos gubernamentales.

\section{Crisis y nuevas circunstancias}

El 27 de febrero de 2002, luego del fin de la convertibilidad, el gobierno nacional cerró una nueva negociación con los gobiernos subnacionales tendiente a sentar los nuevos parámetros en materia de transferencia de recursos a las provincias, meta de déficit y renegociación de la deuda. Esto implicó algunos compromisos básicos, entre los que se cuentan el abandono de sumas fijas de transferencias y su reemplazo por los coeficientes establecidos en la legislación vigente, más el 30\% del impuesto a los créditos y débitos; la renegociación de las deudas provinciales con el objeto de convertirlas en deuda en pesos; el establecimiento de un límite del $15 \%$ a la afectación de recursos coparticipados para el pago de servicios de las deudas reestructuradas; la reducción del déficit fiscal de las jurisdicciones y las limitaciones al endeudamiento provincial.

En el marco de este Acuerdo Federal, el gobierno nacional firmó acuerdos bilaterales con algunas provincias. En 2002 se suscribieron convenios con 17 provincias, en tanto que en 2003 se firmaron acuerdos con 15 jurisdicciones. El Ministerio de Economía ha suscrito con cada una de las provincias lo que ha denominado Programa de Financiamiento Ordenado (PFO), por el cual se les otorga financiamiento mensual para atender los déficit financieros acordados y los servicios de amortización de la deuda pública correspondientes al año en curso.

La firma del acuerdo de febrero de 2002 permitió que las provincias mejoraran su posición fiscal relativa por dos motivos: primero, el retorno al régimen de distribuciones automáticas y por coeficiente que regía con anterioridad al Compromiso Federal de 1999, en un contexto de crecimiento del nivel de los precios (en 2002) y del producto (en 2003); y, segundo, el menor pago de servicios gracias al canje de deuda y al límite de $15 \%$ establecido para la destinación de recursos coparticipados a los servicios de la deuda.

En consecuencia, y con el objeto de ilustrar los cambios consolidados en la política fiscal a partir de la crisis, debe señalarse que ha habido una fuerte mejora fiscal, básicamente por tres factores: el menor pago 
de servicios de la deuda, la caída en el nivel de remuneraciones y prestaciones de la seguridad social (en términos reales y como porcentaje del PIB), y el aumento de la recaudación debido en gran medida a la incorporación de recursos extraordinarios sólo parcialmente coparticipables (derechos de exportación e impuesto al cheque). Esto ha permitido un mejoramiento considerable del resultado primario de todos los niveles de gobierno y, a su vez, cierto margen para el incremento del gasto asistencial destinado a paliar la grave situación social.

En lo que respecta al nivel y la estructura del gasto, el gráfico 1 -que aparece en la sección II.1muestra el cambio en los diferentes niveles de gobierno ante el fin del programa de convertibilidad y la posterior crisis. Al comparar datos para los años 2000 y 2002 se ve que —más allá de la caída del gasto en los tres niveles de gobierno liderada por la reducción de los pagos de intereses de la deuda pública (a nivel del gobierno nacional disminuyeron 40,4\%) - el único rubro que muestra crecimiento es el correspondiente al "otro gasto social" del gobierno nacional $(57,4 \%)$. Este renglón es el que incluye el Programa Jefes y Jefas de Hogar Desocupados. Sobre los restantes destinos del gasto influyó la fuerte caída de los salarios reales del sector público y del valor real de las prestaciones previsionales.

Como reflexión de carácter especulativo, podría evaluarse la posibilidad de un proceso incipiente de recentralización de funciones, basada en tres patas: i) el rescate de los gobiernos provinciales por el gobierno central, a través de la renegociación de las deudas de las provincias con un tope para la afectación de recursos provinciales, implica un traspaso de responsabilidades a la Nación; ii) la introducción de programas asistenciales para atender emergencias (teniendo en cuenta las características estructurales de la economía argentina, el empleo y los límites de la seguridad social) sólo pueden ser entendida como un primer paso en una dirección que seguramente se reforzará en los próximos años; y iii) algunos programas de la Nación se están haciendo cargo de deficiencias que no han podido resolver los presupuestos provinciales durante la crisis. Esto último es particularmente notorio en el área de la salud pública a través de la distribución de medicamentos (Programa Remediar) o la distribución de transferencias contra el cumplimiento de metas programáticas (al estilo de donaciones de contrapartida) para financiar la atención de la población materno-infantil en las provincias de menor desarrollo relativo.

\section{IV \\ Conflicto político y debilidad institucional en las relaciones financieras entre la Nación y las provincias}

Son muchas e inevitables las referencias que a lo largo del presente artículo se han efectuado a las modalidades y magnitud del conflicto político subyacente en las relaciones entre niveles de gobierno en Argentina. En las secciones iniciales ya se hizo mención de los orígenes y desarrollo de esa puja. También se ha aludido a algunos aspectos de tales conflictos durante los últimos 15 años, en los cuales los desequilibrios macroeconómicos y la crisis previsional han sido las causas más claras de las dificultades para resolver cuestiones pendientes en las relaciones financieras entre jurisdicciones.

Se sostiene en este trabajo que el período bajo análisis corresponde a uno en el cual se han agotado para el gobierno nacional las fuentes de financiamiento distintas de los recursos tributarios coparticipables. La pugna entre los diferentes niveles de gobierno, desatada en momentos con un alto grado de conflicto político y crisis macroeconómica, ha tenido asimismo su correlato en una gran debilidad institucional en materia de federalismo. Esto ha sido a la vez causa y consecuencia de los problemas del período.

Como señala Bardhan (2001), cuando la debilidad institucional es el resultado de fuertes conflictos distributivos, tanto a los niveles centrales de gobierno como a los gobiernos locales se les hace difícil cumplir con objetivos de políticas públicas. Entre las muchas manifestaciones de tal debilidad referidas a la 
organización federal de Argentina, se ha decidido hacer en este artículo una breve referencia a las que resultaron más notorias durante los últimos 15 años: la proliferación de acuerdos de emergencia en reemplazo de esquemas estables de reparto, y la debilidad institucional en la regulación del endeudamiento de los gobiernos subnacionales.

\section{Proliferación de acuerdos de emergencia en reemplazo de esquemas estables de reparto}

Un rasgo característico de las relaciones entre la $\mathrm{Na}-$ ción y las provincias durante la vigencia de la Ley 23.548 es el predominio de las relaciones entre poderes ejecutivos por sobre las normas legislativas. Esto se manifiesta tanto en los acuerdos de emergencia entre los gobiernos para modificar lo establecido por la legislación vigente, como en la resolución discrecional de situaciones específicas de algunas jurisdicciones por parte de la Nación. Un ejemplo extremo de la tensión institucional que dominó las relaciones interjurisdiccionales, contraponiendo las soluciones parlamentarias con la negociación entre poderes ejecutivos, es la disposición de la Asamblea Constituyente de 1994, nunca cumplida entre los poderes ejecutivos, a negociar y convenir un nuevo régimen de reparto de impuestos.

A lo largo del período se han negociado y firmado varios pactos o acuerdos destinados a hacer frente a las múltiples dificultades afrontadas, desde el financiamiento del sistema previsional hasta la renegociación de la deuda. Todos ellos involucraron acuerdos entre poderes ejecutivos que modificaron la distribución de fondos establecida por esa ley de coparticipación.

En la sección anterior se mencionó la multiplicidad de remiendos o parches con los que el régimen se ha ido modificando hasta llegar al intrincado e irracional diseño que hoy exhibe. Muchos de ellos han sido instrumentados mediante cambios legislativos y otros, los más importantes, han generado modificaciones legislativas con posterioridad a pactos entre los poderes ejecutivos. Siempre que ello ocurrió se generó un espacio amplio para una modalidad de negociación en donde predominaron los aspectos políticos y se incorporaron elementos que no siempre fueron reflejados con transparencia.

Como resultado de esos acuerdos, más las múltiples modificaciones introducidas a la asignación de los diferentes impuestos coparticipables, la distribución de recursos se ha convertido en un conjunto caótico de variados mecanismos de reparto ad hoc que han ido multiplicándose a lo largo de los años. La multiplicidad de mecanismos de distribución no es la respuesta a una similar multiplicidad de objetivos, sino producto de una yuxtaposición de conflictos y pugnas. Lo que según la legislación debiera ser una fórmula con un coeficiente único de reparto para todos los tributos coparticipables (o al menos admitir muy pocas excepciones y de carácter transitorio), se ha transformado en una compleja matriz que vincula tales tributos con variados destinos mediante porcentajes y sumas fijas que son fiel reflejo de la puja distributiva al interior de las cuentas públicas.

Se observa la existencia de tres formas básicas de presiones sobre el esquema de reparto. En primer lugar se hallan las destinaciones de recursos coparticipables propiamente dichos para dar respuesta principalmente a la necesidad de allegar más financiamiento al sistema previsional. En segundo lugar se cuentan las asignaciones de tales recursos al financiamiento de la infraestructura, que ha provenido históricamente de los tributos sobre los hidrocarburos y la energía. Por último, cabe mencionar también las pujas por la distribución de recursos dentro del presupuesto de la administración nacional. Todo ello estaría indicando que, más allá de la pugna entre la Nación y las provincias, hay pujas sectoriales y la pretensión de resolverlas mediante la asignación específica de diferentes impuestos.

\section{Debilidad institucional en la regulación del endeudamiento de los gobiernos subnacio- nales}

Durante la segunda mitad del decenio de 1990, sucesivas decisiones de política nacionales brindaron a las provincias la posibilidad de tener un acceso más fluido a fuentes financieras internas y externas. Puesto que la situación de los mercados de crédito fue propicia a este cambio, hubo un considerable aumento de las deudas provinciales, situación que llegó al límite a fines de 2001.

Durante la década de 1990 el endeudamiento provincial estuvo regido por una serie de normas de diferente alcance y origen institucional. ${ }^{10} \mathrm{La}$ mayor parte

\footnotetext{
${ }^{10}$ La Constitución Nacional, en su artículo 124, otorga a las provincias la facultad de celebrar convenios internacionales, debiendo cumplir con ciertos requisitos, y aclara que ellas "podrán también celebrar convenios internacionales en tanto no sean incompatibles con la política exterior de la Nación y no afecten las facultades delegadas al Gobierno Federal o el crédito público de la Nación con el conocimiento del Congreso Nacional."
} 
de las provincias contaba con límites establecidos por sus propias constituciones sobre el nivel de endeudamiento permitido. Estas restricciones incluían mecanismos de autorización para el endeudamiento, restricciones al uso de los fondos (por ejemplo, prohibición de destinarlos a financiar gasto corriente) o limitaciones al nivel de los servicios. ${ }^{11}$

Al mismo tiempo, en el ámbito nacional existía un conjunto de regulaciones sobre el endeudamiento de las provincias. La reforma de la Carta Orgánica del Banco Central de la República Argentina prohibió el otorgamiento de créditos de las entidades financieras al sector público sin autorización del Ministerio de Economía. Para los créditos en moneda extranjera, los gobiernos provinciales necesitaban una aprobación $\mathrm{ad}$ hoc de las operaciones concertadas con el sistema financiero, según lo establecido por la resolución 1075/ 93 de dicho ministerio. A su vez, esta resolución establecía un mecanismo de pago automático de los servicios de la deuda mediante el acceso directo a los recursos coparticipados que depositaba el gobierno nacional en las cuentas provinciales. Este mecanismo facilitó el acceso de las provincias a los mercados financieros, al otorgar una garantía confiable, pero el hecho de no haberlo aplicado con el objetivo de asegurar la solvencia financiera de las jurisdicciones incentivó en algunos casos un endeudamiento excesivo. Sólo con la implementación del Programa de Asistencia Financiera y Fiscal de principios de 2000 y con los Programas de Financiamiento Ordenado de 2002, este mecanismo pudo ser utilizado en un conjunto de provincias como un medio efectivo de limitar el endeudamiento para cumplir con la reducción de desequilibrios acordada por cada gobierno provincial con el gobierno nacional.

La mecánica de endeudamiento utilizada por las provincias desde principios del decenio de 1990, utilizando las transferencias de recursos de coparticipación como garantía, ha tenido dos efectos: por un lado, ha alentado un creciente endeudamiento provincial al facilitar el acceso a los mercados de crédito; por el otro, ha restringido fuertemente la provisión de bienes y servicios sociales por parte de las provincias, al modi-

11 Para un tratamiento exhaustivo del tema, véase Cetrángolo, Jiménez y otros (2002). ficar el proceso presupuestario provincial. Las provincias perdieron su capacidad de establecer prioridades presupuestarias mes a mes, ya que el pago a los acreedores se efectúa en forma automática; por lo tanto, deben encontrar financiamiento adicional para afrontar los gastos de funcionamiento de cada período.

En el cuadro 4 se presentan los porcentajes de los recursos de coparticipación destinados a pagar deuda en 2001, antes de la cesación de pagos. Allí se puede observar la exigua capacidad de manejo presupuestario con que algunas provincias debían encarar sus gastos de funcionamiento luego del pago de servicios de deuda. Posteriormente, con la firma del acuerdo de febrero de 2002 se incorporó un límite del 15\% a la afectación motivada por deudas renegociadas, quedando a cargo de la Nación las obligaciones que superaran ese porcentaje.

CUADRO 4

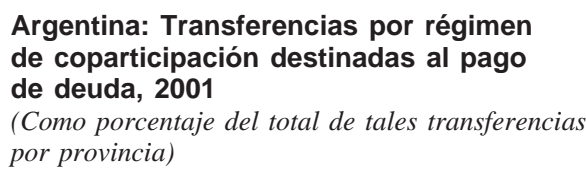
por provincia)

\begin{tabular}{lr}
\hline Jurisdicción & $\%$ \\
\hline Buenos Aires & 1,6 \\
Ciudad de Buenos Aires & 0,0 \\
Catamarca & 57,2 \\
Córdoba & 2,8 \\
Corrientes & 55,4 \\
Chaco & 39,0 \\
Chubut & 29,5 \\
Entre Ríos & 22,8 \\
Formosa & 68,2 \\
Jujuy & 91,8 \\
La Pampa & 2,4 \\
La Rioja & 50,8 \\
Mendoza & 60,5 \\
Misiones & 48,6 \\
Neuquén & 9,2 \\
Río Negro & 97,3 \\
Salta & 73,5 \\
San Juan & 41,3 \\
San Luis & 27,5 \\
Santa Cruz & 4,7 \\
Santa Fe & 4,0 \\
Santiago del Estero & 36,6 \\
Tucumán & 85,3 \\
Tierra del Fuego & 37,9 \\
\hline
\end{tabular}

Fuente: Elaboración propia. 


\section{V}

\section{Reflexiones finales}

En este artículo se ha mostrado que los problemas que enfrenta hoy la organización federal argentina son producto de una yuxtaposición de problemas estructurales, de reformas efectuadas en el decenio de 1990 y de la crisis tras el fin de la convertibilidad. Se ha insistido en la importancia de considerar las características políticas e institucionales del problema, influidas por una combinación de elementos en la cual la debilidad institucional es contraparte y espejo de una fuerte pugna política en torno a las cuestiones federales, cuyos orígenes deben buscarse en la formación misma de la nación argentina.

La dinámica misma del conflicto político e institucional ha sido retroalimentada por las características de la extendida crisis macroeconómica que, con momentos de mayor o menor tensión, ha dominado la historia argentina de las últimas décadas. En relación con el tema de este trabajo, la trayectoria de la crisis previsional y su demanda creciente de financiamiento, así como una estructura tributaria insuficiente para financiar de manera adecuada las políticas públicas que llevan adelante los diferentes niveles de gobierno, han constituido los factores dominantes del conflicto.

Se ha visto que mientras el sector público nacional logró financiamiento adicional para cubrir las nuevas demandas de políticas públicas, la expansión de actividades gubernamentales que acompañó al desarrollo argentino no chocó con el funcionamiento federal del país. Pero al agravarse la crisis macroeconómica se agotaron las fuentes de financiamiento distintas de la masa de recursos coparticipables (rentas aduaneras, impuesto inflación, impuestos sobre los combustibles, cargos sobre la nómina salarial, excedente previsional, endeudamiento, privatizaciones), estalló la crisis fiscal (impulsada por la deuda y la crisis previsional) y el conflicto en torno al reparto de recursos coparticipables se hizo cada vez más grave y complejo.

$\mathrm{El}$ agotamiento de fuentes de financiamiento que no fuesen los recursos coparticipables para enfrentar las nuevas funciones que ha tenido que ir asumiendo la jurisdicción nacional, el incremento en el número de jurisdicciones subnacionales que participan del reparto y el creciente desnivel de erogaciones y recursos entre jurisdicciones, fueron factores estructurales que, sumados a los rasgos típicos de las últimas décadas (crisis macrofiscal y del sistema previsional, y pugna política) explican el alto grado de conflicto que dominó las relaciones financieras entre la Nación y las provincias.

En el decenio de 1990 cobraron significación a su vez problemas de otro tipo, relacionados con la puesta en marcha de un programa macroeconómico con tipo de cambio fijo cuya prioridad debe ser hoy revisada. La urgencia de mejorar la competitividad de los sectores de actividades transables en el ámbito internacional impulsó el debate acerca de la reforma de los tributos provinciales sobre los ingresos brutos, principal fuente de ingresos propios de las provincias. Sin desconocer la importancia del tema, es discutible que el grado de premura que alcanzó en esa época se mantenga hoy, bajo un programa macroeconómico que contempla una muy diferente configuración de precios relativos; no obstante, se debe seguir trabajando en él sin las urgencias de entonces.

Asimismo, en el decenio de 1990 se lograron consensos que hoy deben ser revisados. Lamentablemente, la posibilidad de introducir un esquema que incorpore nuevos criterios de reparto para los incrementos en la recaudación -iniciativa que tuvo amplio apoyo en esos años-, hoy plantea la necesidad de acuerdos más difíciles de lograr: si los niveles que se deben respetar son nominales o reales y, en todo caso, qué índice de precios utilizar.

Llama la atención que, ante la dificultad de encontrar una solución a los problemas derivados de la ausencia de un mecanismo explícito, estable y transparente de distribución de recursos, las expectativas generadas por el compromiso constitucional de sancionar un nuevo régimen llevaron a presiones para incorporar en ese régimen, ya de difícil aprobación, nuevos temas que hicieron la empresa aún más compleja. Así, se agregaron temas tales como la nueva institucionalidad fiscal, la necesidad de redefinir y armonizar las potestades tributarias, la ausencia de reglas fiscales y la construcción de instrumentos para atenuar los efectos del ciclo.

En cambio, hay dos problemas estructurales que, como se expuso más atrás, constituyen una seria debilidad del funcionamiento federal de Argentina y que, lamentablemente, no han sido objeto de un necesario 
debate: los problemas de financiamiento de las políticas sociales compensatorias y los desequilibrios productivos. En el primer caso, hay que trabajar en la corrección de las deficiencias observadas en el pasado proceso de descentralización del gasto social, especialmente en salud y educación básica. Impulsada por urgencias fiscales, la Nación terminó por desentenderse de las políticas de compensación y coordinación del gasto social, lo que tuvo un fuerte impacto adverso sobre la equidad. Para resolver estos problemas se requiere el diseño previo de políticas sectoriales, lo que se hizo en la década de 1990 en materia de educación y se está discutiendo actualmente respecto a salud. Pero si se quiere que esas iniciativas prosperen, el futuro esquema de transferencias debe tomar nota de esas políticas e incorporar en el debate sus necesidades financieras.

En el segundo caso, existen fuertes disparidades productivas provinciales. Dada la enorme brecha de desarrollo que se observa entre las distintas provincias argentinas, no cabe imaginar que la correspondencia fiscal (es decir, que los gobiernos subnacionales financien su gasto con recursos propios) sea la solución a los problemas de incentivos. Es impensable que las provincias menos desarrolladas puedan asegurar una provisión de bienes públicos similar a las de aquellas de mayor desarrollo sin contar con la asistencia (no sólo financiera) de la Nación. Esto a su vez remite a los problemas de promoción del desarrollo productivo y al papel de los gobiernos locales.

Por lo demás, es preciso identificar los problemas que caracterizan a la nueva coyuntura. El fin de la convertibilidad estuvo acompañado por un replanteamiento de las funciones de los diversos niveles de gobierno. Cuatro rasgos deben tenerse en cuenta al respecto:

- Los cambios en la estructura tributaria, que influyeron significativamente en el logro de un considerable superávit primario de recursos tributarios no coparticipables (aduaneros) o de aquellos con una coparticipación reducida (créditos y débitos bancarios).

- La creciente importancia en las finanzas nacionales del gasto en asistencia social.

- El anuncio de una nueva modificación del sistema previsional.

- El proceso de renegociación de deudas y el traspaso a la Nación de buena parte del peso de las deudas provinciales.

Es difícil imaginarse un debate sobre un nuevo esquema de reparto entre la Nación y las provincias que intente generar un acuerdo de mediano plazo sin pronunciarse antes sobre la probabilidad de que estos fenómenos persistan y que, como todo lo hace pensar, se mantengan en el futuro las importantes partidas presupuestarias destinadas, por ejemplo, a la asistencia social $^{12}$ (en especial al Programa Jefes y Jefas de Hogar Desocupados), así como las nuevas transferencias a las provincias destinadas a apoyar la provisión de servicios de salud pública (programas Remediar y Seguro Materno-Infantil). Si esto es así, estamos en presencia de un nuevo reparto de funciones que exigirá reexaminar el federalismo y las transferencias intergubernamentales. Por su parte, el replanteamiento previsional puede estar asociado a la introducción de prestaciones asistenciales a los mayores que no logren acreditar 30 años de empleo formal. Estas seguramente serán crecientes y a cargo de la Nación.

Un elemento que no debemos olvidar se refiere al funcionamiento de la macroeconomía durante los próximos años y su impacto sobre las finanzas de los diferentes niveles de gobierno. La particular coyuntura fiscal de hoy está sustentada por un conjunto de precios relativos, en el cual el elevado tipo de cambio permite el cobro de impuestos extraordinarios no coparticipables, y la caída en términos reales de los salarios públicos y prestaciones de la seguridad social ha hecho posible un importante superávit fiscal (además del financiamiento de nuevas funciones). Lo excepcional de la coyuntura obliga a ser cuidadosos en la introducción de reglas de reparto de recursos que puedan ser afectadas en el futuro cercano.

Durante los últimos meses, no obstante, volvió a cobrar impulso el debate acerca de una eventual ley de coparticipación y se examinó la posibilidad de lograrlo efectivamente. Tomando en cuenta la analogía frecuentemente utilizada entre el esquema de reparto vigente y un laberinto, en algunos casos se recurrió a una conocida frase de Leopoldo Marechal para propiciar una nueva salida mágica: "de todo laberinto se sale por arriba". 13

La nueva coyuntura requiere un federalismo flexible que atienda a las diferentes demandas de cada provincia y se pueda adaptar a las cambiantes circunstancias de la economía argentina. No hay que pensar necesariamente en un instrumento que intente solucionar todos los problemas a la vez. Se cree conveniente, en cambio, discutir, concordar y poner en práctica las

\footnotetext{
12 En especial al Programa Jefes y Jefas de Hogar Desocupados.

13 "Laberinto de amor", poema publicado por Sur en 1944.
} 
diferentes soluciones a problemas específicos que con el tiempo puedan despejar el terreno para resolver los problemas más difíciles de abordar. La construcción de un federalismo moderno es una tarea cotidiana y la aprobación de una determinada ley no resuelve mágicamente problemas de larga data.

Bibliografía

Bardhan, P. (2001): Distributive conflicts, collective action, and institutional economics, en G. Meier y J. Stiglitz (comps.), Frontiers of Development Economics: The Future in Perspective, Washington, D.C., Banco Mundial/Oxford University Press.

Bidart Campos, G. (1993): El federalismo argentino desde 1930 hasta la actualidad, en M. Carmagnani (coord.), Federalismos latinoamericanos: México/Brasil/Argentina, México, D.F., El Colegio de México/Fideicomiso Historia de las Américas/ Fondo de Cultura Económica.

Botana, N. (1993): El federalismo liberal en Argentina: 1852-1930, en M. Carmagnani (coord.), Federalismos latinoamericanos: México/Brasil/Argentina, México, D.F., El Colegio de México/Fideicomiso Historia de las Américas/Fondo de Cultura Económica.

Cetrángolo, O. y J.P. Jiménez (1995): El conflicto en torno a las relaciones financieras entre la Nación y las provincias, Estudios, $\mathrm{N}^{\circ} 9 \mathrm{y} \mathrm{N}^{\circ} 10$, Buenos Aires, Centro de Estudios para el Cambio Estructural (CECE).

(1998): Algunas reflexiones sobre el federalismo fiscal en la Argentina, Desarrollo económico, número especial, vol. 38 , Buenos Aires, Instituto de Desarrollo Económico y Social (IDES).

Cetrángolo, O., J.P. Jiménez y otros (2002): Las finanzas públicas provinciales: situación actual y perspectivas, serie Estudios y perspectivas, $N^{\circ} 12$, LC/L.1800-P, Buenos Aires, Oficina de la CEPAL en Buenos Aires, diciembre. Publicación de las Naciones Unidas, $\mathrm{N}^{\circ}$ de venta: S.02.II.G.110.

Consejo Federal de Inversiones (1996): Escudos provinciales de la Argentina, Buenos Aires.

Decressin, J. (1999): Regional Income Redistribution and Risk Sharing: How Does Italy Compare in Europe?, IMF Working Paper, WP/99/123, Washington, D.C., Fondo Monetario Internacional.

Gatto, F. y O. Cetrángolo (2003): Dinámica productiva provincial a fines de los años noventa, serie Estudios y perspectivas, $\mathrm{N}^{\circ}$ 14, LC/L.1848-P, Buenos Aires, Oficina de la CEPAL en Buenos Aires. Publicación de las Naciones Unidas, $\mathrm{N}^{\circ}$ de venta: S.03.II.G.19.

Porto, A. (1990): Federalismo fiscal. El caso argentino, Buenos Aires, Instituto Torcuato Di Tella/Editorial Tesis.

Presman, J. (1992): La coparticipación de impuestos: del federalismo fiscal al centralismo menemista, Estudios, $\mathrm{N}^{\circ}$ 5, Buenos Aires, Centro de Estudios para el Cambio Estructural (CECE).

Silva, I. (2003): Disparidades, competitividad territorial y desarrollo local y regional en América Latina, serie Gestión pública, $\mathrm{N}^{\circ}$ 33, LC/L.1882-P, Santiago de Chile, ILPES (Instituto Latinoamericano y del Caribe de Planificación Económica y Social). Publicación de las Naciones Unidas, $\mathrm{N}^{\circ}$ de venta: S.03.II.G.47. 